\title{
Amor e moralidade: um estudo com participantes de 5 a 70 anos*
}

\author{
Ariadne Dettmann Alves ${ }^{l}$ \\ Heloisa Moulin de Alencar ${ }^{2}$ \\ Antonio Carlos Ortega ${ }^{3}$ \\ Universidade Federal do Espirito Santo
}

Refletindo sobre importância das virtudes no estudo da moralidade, objetivamos investigar os juízos dos participantes no que diz respeito a concepção do amor. Entrevistamos sete pessoas, com idades que compreende desde a infância até a velhice. Pesquisamos o que cada um considerava como exemplo de amor, e destes qual seria o mais e o menos importante. Constatamos que os participantes mais novos destacam um amor direcionado a outrem, sem definir quem seria esse outro. Entretanto, os mais velhos citam mais família e amigos. As justificativas para a escolha dos exemplos de amor ressaltam a experiência pessoal ou exemplos de outras pessoas. Apesar de o exemplo escolhido como mais importante remeter a um amor a Deus ou a uma preocupação com o outro, essa escolha relaciona-se às consequiências que este traria à própria pessoa. Nesse trabalho exploratório, procuramos destacar a amplitude e importância do estudo desse tema no campo da moralidade.
Reflecting on the importance of virtues in the study of morality, we aim to investigate the participants' judgments regarding the concept of love. We interviewed seven people, with ages comprising from childhood to elderly. We researched what each one regarded as an example of love, and of those, which would be the most and least important. We found that younger participants highlighted a love directed to others, without defining who this other would be. However, the older ones cite more family and friends. The justifications for the choice of the examples of love emphasize personal experience or examples of other people. Although the example chosen as most important refers to a love of God or a concern with another, this choice relates to the consequences that this would bring to oneself. In this exploratory work, we look to highlight the extent and importance of studying this subject in the field of morality.

\footnotetext{
* Love and morality: a study with participants from 5 to 70 years old

${ }^{1}$ Mestranda do Programa de Pós-Graduação em Psicologia da UFES. Endereço para correspondências: Av. São Paulo, 1270, apto 1002, Praia da Costa, Vila Velha, ES, 29101-300 (alves.ariadne@gmail.com). Os autores agradecem à CAPES pelo apoio financeiro concedido.

${ }^{2}$ Professora do Departamento de Psicologia Social e do Desenvolvimento e do Programa de PósGraduação em Psicologia da UFES.

${ }^{3}$ Professor Colaborador e Pesquisador do Programa de Pós-Graduação em Psicologia da UFES.
} 
Palavras-chave: Desenvolvimento moral - Juízo moral - Virtude - Amor
Keywords: Moral development Moral judgment - Virtue - Love

\section{Introdução}

$\mathrm{P}$ iaget (1932/1994) dedicou um livro ao tema do desenvolvimento moral, intitulado $O$ juízo moral na criança. Essa obra serviu de referência para estudiosos da psicologia da moralidade. Como afirma La Taille (1994) no prefácio desse livro, por meio da moralidade infantil, o objetivo de Piaget é pensar a moralidade humana. A partir de situações de jogos e histórias envolvendo conteúdos morais, Piaget (1932/1994) formulou a hipótese de que o sujeito passa de uma fase de anomia (pré-moral) a uma fase de heteronomia, podendo chegar à fase de autonomia, se as interações com o meio forem favoráveis.

Até os quatro anos de idade, aproximadamente, a criança ainda não penetrou no mundo da moral, estando na fase da anomia (PIAGET, 1932/1994). A criança é inserida em um universo de regras sociais, mas essas regras não são ainda associadas a valores como o bem e o mal, o certo e o errado. A entrada na moral ocorre quando a criança começa a conceber, por volta dos quatro anos, que há ações que devem ou não devem ser realizadas, se referindo à idéia de que as regras apontam para ações que são boas ou más, certas ou erradas. Neste momento, a criança encontra-se na fase da heteronomia.

Nessa fase, a criança respeita as regras impostas pelos adultos por medo e amor. Medo de perder o amor e proteção dos pais e medo das punições, e pelo amor, devido ao apego e admiração que a criança tem pelos pais, ou pelas pessoas para ela significativas. Aqui há menção do amor, mas o que sobressai é o medo. Assim, obedecer às regras seria determinado "pelo amor" do outro ou "pelo medo de perder o amor". Existe, portanto, uma relação de coação, predominando o respeito unilateral. A criança tende a interpretar as regras ao pé da letra, não as compreende, e as considera imutáveis. Privilegia as consequiências da ação, não levando em conta a intenção que a motivou (PIAGET, 1932/1994).

Por volta dos oito, nove anos, a criança pode começar a apresentar indícios de autonomia. As relações de coação são substituídas pelas relações de cooperação, agindo por princípios de reciprocidade e igualdade entre os parceiros. Há o predomínio do respeito mútuo. Nessa fase, a criança passa a compreender e interpretar as regras. Torna-se capaz de fazer suas avaliações morais, passando a julgar a partir de seus princípios. A intencionalidade passa a ser o critério para o juízo moral (PIAGET, 1932/1994).

Além de relacionar o amor à moral heterônoma, Piaget (1932/1994) faz menção a algumas virtudes como o "perdão", a "generosidade" e o "amor 
propriamente dito", ressaltando a sua importância no campo da moralidade. Constatamos em sua obra, portanto, duas referências ao amor: o amor relacionado à obediência da fase de heteronomia e o "amor propriamente dito". A este último, Piaget (1932/1994) se refere como sendo uma virtude. Já o primeiro, estando relacionado a coação, não seria virtuoso, uma vez que não estaria aspirando a prática do bem. Ou seja, nem todo amor é virtuoso.

Mas antes de discorrermos sobre o tema das virtudes, devemos nos remeter a uma discussão do que seja moral e ética. Podemos encontrar diversas definições para a moral e a ética, contudo, para esse artigo analisaremos o proposto por La Taille (2006). Esse autor afirma que a moral responderia a pergunta "como devo agir?", ou seja, relaciona-se a deveres. Afirma ser a moral um sistema de regras e princípios que restringe a liberdade individual, sendo de caráter obrigatório, cujo objetivo é garantir a harmonia do convívio social. Há no plano da moral o sentimento de obrigatoriedade, que pode receber diversos conteúdos. Esse sentimento de obrigatoriedade não garante saber qual o dever a ser seguido.

A ética relaciona-se à busca de uma "vida boa", "uma vida que vale a pena ser vivida" (LA TAILLE, 2006; p. 30), ou seja, uma vida que faça sentido. Isso remete a "expansão de si próprio". Desta forma, responderia a pergunta "que vida quero viver?". Essa pergunta relaciona-se a outra, "para que viver?", resgatando o sentido da vida. Para responder a isso, é necessário pensar "quem ser", remetendo a identidade pessoal. Assim, "escolher um sentido para a vida e formas de viver é escolher a si próprio, é definir-se como ser" (p. 45).

Toda ética contém uma moral, pois cabe à moral regrar a vida em sociedade. A moral não responde ao que é ser feliz, mas quais são os deveres a serem obedecidos para que a felicidade individual tenha legitimidade social (LA TAILLE, 2006).

Desta forma, a articulação dos planos moral e ético passa pela relação dos processos de "sentimento de obrigatoriedade" e "expansão de si". O plano ético engloba o plano moral, pois a existência e a força do sentimento de obrigatoriedade moral dependem dos rumos que toma a expansão de si próprio. Assim, para compreendermos os comportamentos morais dos indivíduos, é necessário conhecer a perspectiva ética que adotam (LA TAILLE, 2006). Portanto, procuramos definir conteúdos para a moral, e não para a ética, pois é a moral que confere legitimidade às opções de "vida boa", isto é, "confere-lhes as condições necessárias para que mereçam o nome de ética" (LA TAILLE, 2006; p. 60).

La Taille (2006) discute a dimensão intelectual da ação moral, o "saber fazer moral", e a dimensão afetiva da ação moral, o "querer fazer moral". A dimensão intelectual é condição necessária às ações reconhecidas como morais. Mas, para que o "saber fazer moral" se torne ação, é necessário o "querer fazer moral", ou seja, a vontade de agir e a intenção com a qual se age. 
Assim, La Taille (2006) elege seis sentimentos que inspiram o "querer agir moral": medo, amor, confiança, simpatia, indignação e culpa. O medo e o amor são indissociáveis para o sentimento de obrigatoriedade presente na ação moral. Como mencionamos anteriormente, na fase de heteronomia proposta por Piaget (1994) a criança respeita as regras impostas pelo adulto por medo e amor às figuras de autoridade. Desta forma, este binômio explicaria o "querer fazer" heterônomo.

La Taille (2006) ao afirmar que o amor motiva a ação moral, diferencia o "amor de si" do "amor próprio". Ele discute que, sendo o "amor próprio" uma supervalorização do eu, este não é suficiente para garantir a moral. Mas considerando "amor de si" como referência às qualidades do eu, esta é condição necessária para a moralidade.

Além dessas considerações, La Taille (2006) se refere a Aristóteles (384322 a.C.) para afirmar que a ética está relacionada ao cultivo das virtudes. Sobre o estudo das virtudes, La Taille (2000) aponta que sua importância se dá por um interesse universal ao tema, pela relevância psicológica na construção da moral na criança e pela sua inserção no que seja moral ou ética. Passemos agora, para algumas considerações sobre as virtudes, e, posteriormente sobre a virtude do amor.

Comte-Sponville (1999) afirma que "a virtude de um homem é o que o faz humano" (p. 8), é o poder específico de afirmar a sua humanidade. Assim, a virtude é nossa maneira de ser e de agir humanamente. A virtude não é o bem absoluto, nem o bem em si para contemplar, é o bem para se fazer. Assim, segundo Comte-Sponville (1999), há várias virtudes, e não poderíamos reduzir todas elas a uma só, nem se contentar com uma delas - "são nossos valores morais, se quiserem, mais encarnados, tanto quanto quisermos, mas vividos, mas em ato" (p. 10).

Dentro desse tema das virtudes, escolhemos estudar a virtude do amor. Comte-Sponville (1999) afirma que "agir moralmente é agir como se amássemos" (p. 243). Assim, só necessitamos da moral, porque nos falta amor. O dever nos obriga a fazer aquilo que, se houvesse amor, essa própria ação seria livremente realizada, sem coerção. Além disso, quando há o amor, as outras virtudes seguem-se espontaneamente.

Buscando definições para a palavra 'amor', encontramos diversos significados. Apenas no Dicionário Houaiss (2001), o amor pode corresponder a forte afeição por outra pessoa, relação amorosa, ato sexual, ou ainda, amizade, caridade, compaixão, demonstração de zelo, dedicação ou fidelidade.

Já para Comte-Sponville (1999), para definir 'amor' devemos falar em três tipos: eros, philia e ágape. Eros é o amor que sofremos, é a paixão. Rico em sofrimento, falta e possessividade. Esse amor é egoísta, não sendo assim uma virtude, pois "estar apaixonado é amar o outro para seu próprio bem” (p. 257). 
Quem assim ama quer possuir, se ama o que lhe deseja e falta. Esse amor não é "completitude, mas incompletitude. Não fusão, mas busca. Não perfeição plena, mas pobreza devoradora" (p. 252). Esse amor é um desejo, mas este desejo é falta.

Philia é o amor que fazemos ou damos, é ação. Não é uma paixão, é uma virtude, é a amizade. Comte-Sponville (1999) cita Aristóteles (384-322 a.C.) que, em seu livro Ética a Nicômaco, afirmou que a amizade é condição da felicidade, e sem ela a vida seria um erro. Consiste em amar, antes de ser amado. Não é falta nem fusão, é igualdade, partilha e fidelidade. Philia não se reduz à falta ou à paixão (ao eros). É a alegria da mãe ao amar seu filho, é também o amor paterno, fraterno ou filial. Pode ser o amor entre marido e mulher, quando se deposita alegria na virtude do outro. É desejar o bem a seus amigos por amor a eles. Eros e philia quase sempre se misturam, principalmente entre homens e mulheres, assim, "podemos nos regozijar (philia) com o que nos falta (erôs) [sic], querer possuir (erôs) [sic] aquilo cuja existência já é uma felicidade (philia)" (COMTE-SPONVILLE, 1999; p. 275). Podemos, ao mesmo tempo, amar apaixonadamente e alegremente.

Ágape é o amor divino, amor universal. É derivado do verbo agapan, que significa acolher com amizade, amar, querer bem. É o esquecimento de si, o sacrifício de seu prazer, de seu bem-estar ou de seus interesses. É o amor espontâneo, desinteressado, gratuito. Não é o amor que se dá a um amigo (como philia), mas ao desconhecido ou ao inimigo. Distingue-se de eros, pois este é sempre egoísta, motivado pelo que lhe falta, encontra sempre seu valor no outro, sua esperança no outro. Philia também nunca é totalmente desinteressada, gratuita ou espontânea, como é ágape (COMTE-SPONVILLE, 1999).

O amor ágape cria valores, não os constata. É o princípio criador de valor. Ele ama e, assim, confere valor. Portanto, "o homem amado por Deus não tem nenhum valor em si; o que lhe dá um valor é o fato de Deus amá-lo" (COMTESPONVILLE, 1999, p. 300). Assim, o amor comanda, ele não pode ser comandado. Ele é toda a lei, e mais precioso que a ciência, a fé ou a esperança. Podemos, portanto, resumir três maneiras de amar (tipos de amor, ou gradações no amor): eros (carência), philia (regozijo) e ágape (caridade).

Para Betto e Cortella (2007) o amor engloba a esperança e a fé. Assim, toda relação seria uma relação de confiança, de espera, de expectativa e desejo. Referem-se ao mandamento de Jesus, "Ame ao próximo como a si mesmo", para afirmar que não há como gostar de alguém sem antes gostar de si. Discutem que na experiência amorosa pode haver, de fundo, uma relação de reciprocidade, "amo enquanto sou amado" (p. 60). Mas também há a proposta de Jesus, do amar os inimigos, "amo quem não me ama" (p. 60). Essa seria a máxima do amor, querer o bem de todos, mesmo que alguém me proporcione o mal. Questionam, ainda, que não há (e deveria haver) educação para o amor. 
Por sua vez, Keleman (1996) afirma que aprendemos, ou não, na família o que é o amor, por meio de ações de cuidar e importar-se, de compartilhamento e companheirismo. Desta forma, podemos aprender o que é o amor na família, nas interações entre crianças e com os adultos que as criam. Afirma que passamos por quatro estágios de amor: cuidar, importar-se, compartilhar e cooperar.

O primeiro estágio (cuidar) requer alguém disponível para prover alimento e calor. No nível seguinte (importar-se), ser objeto de interesse dos pais cria um sentimento de pertença, ou seja, a criança é parte de uma comunidade. No terceiro estágio (compartilhar) forma-se um relacionamento entre os organismos coordenados um com o outro, gerando um sentimento de estar acompanhado. E no quarto estágio (cooperar) é o momento em que as pessoas se comprometem com algo maior do que elas. É diferente do acompanhamento, inclui acompanhar, mas constitui outra etapa. Assim, esses quatro estágios formam a atividade e os sentimentos que chamamos de amor. Os estágios geram um vínculo e desenvolvem sentimentos de pertença (KELEMAN, 1996).

Ao contrário de Keleman, Bauman (2004) afirma que não se aprende a amar, da mesma forma que não se aprende a morrer. Também relaciona o amor ao cuidar, preservar o objeto cuidado. Significaria proteger, estar a serviço, colocar-se à disposição, aguardar a ordem. Declara que para se ter amorpróprio, é necessário ser amado. Ou seja, o que amaríamos é a esperança de sermos amados, de sermos dignos do amor.

Bauman (2004) discorre sobre um "amor líquido". É possível a pessoa amar mais de uma vez; apaixonar e desapaixonar seria algo fácil de acontecer. Não defende o amor eterno, para ele devemos saber até quando permanecer na relação, da mesma forma que fazem os acionistas no mercado de ações, de acordo com o retorno que temos e se propostas melhores aparecerão. Assim, se investimos numa relação esperamos receber algo em troca.

Estaríamos, assim, frente a uma fragilidade das relações interindividuais. La Taille (2009) reflete sobre as idéias de Bauman e afirma que estamos vivendo numa cultura sem valores estáveis, tendo a moral pouca importância. O outro é invisível ou visto como platéia, assim, as relações são superficiais.

Apesar disso, podemos pensar em alguns "poréns", como propõe La Taille (2009) afirmando que não estamos destinados à infelicidade. Apesar de o avanço tecnológico ter permitido uma superficialidade nas comunicações, temos um enriquecimento sobre a possibilidade de nos comunicarmos com diferentes pessoas, a oportunidade de conhecer inúmeros lugares e culturas. O mundo real está ao nosso alcance.

Além disso, La Taille (2009) ressalta que muito tem se falado em moral. Vemos uma preocupação na defesa dos Direitos Humanos, sensibilidade frente aos que sofreram alguma deficiência, organizações que procuram dar apoio e visibilidade aos que sofrem miséria e exclusão. 
Pensando nisso, La Taille (2009) reflete sobre o papel da escola, e destaca a importância do trabalho sobre as virtudes, uma vez que estas não são talentos inatos ou algum traço de personalidade tendo raízes biológicas. São decorrentes de um trabalho de autoaperfeiçoamento, e, portanto, ao alcance de todos.

Assim, a partir da discussão desses autores, nossa intenção é explorar a concepção que as pessoas têm do amor. Nesse trabalho nosso objetivo é, portanto, investigar os juízos, no que diz respeito à concepção do amor, do período da infância até a velhice. Para isso, pesquisamos o que cada participante considerava como exemplo de amor, e dos citados qual seria o mais e o menos importante.

\section{Método}

\section{Participantes}

Participaram dessa pesquisa sete pessoas, com idade entre 5 e 70 anos e de ambos os sexos, conforme assinala a Quadro 1.

\section{Quadro 1}

Características dos participantes da pesquisa.

\begin{tabular}{lll}
\hline Nome Fictício $^{4}$ & Idade & Sexo \\
\hline Caio & 5 anos & Masculino \\
Daniela & 10 anos & Feminino \\
Quênia & 15 anos & Feminino \\
Vanessa & 20 anos & Feminino \\
Thiago & 30 anos & Masculino \\
Célio & 50 anos & Masculino \\
Silvia & 70 anos & Feminino \\
\hline
\end{tabular}

As idades foram selecionadas de forma a abranger todas as fases de desenvolvimento: infância, adolescência, idade adulta e velhice (COLL et al., 2004; SHAFFER, 2005; BEE, 1997), possibilitando desta forma alcançar o objetivo de investigar a concepção de amor da infância até a velhice.

\footnotetext{
${ }^{4}$ Escolhemos o nome fictício dos participantes de acordo com a primeira letra correspondente a sua idade, por exemplo, para a menina de 10 anos escolhemos um nome iniciado com "d" (Daniela). Sendo que, para diferenciar os participantes de 5 e 50 anos, utilizamos 'Ca' para o de 5 anos (Caio) e 'Ce' para o de 50 anos (Célio).
} 
Como se trata de um trabalho exploratório, optamos por entrevistar uma pessoa de cada idade escolhida.

\section{Instrumento e procedimento}

Realizamos entrevistas individuais, semi-estruturadas, de acordo com o método clínico proposto por Piaget (1932/1994, 1926/2005). Apresentamos no Quadro 2 o roteiro da entrevista.

\section{Quadro 2}

Roteiro da entrevista.

1.a Cite exemplos de amor.

1.b Por que isso é um exemplo de amor?

2.a Dos exemplos que você citou, qual você considera o mais importante?

2.b Por quê?

3.a Dos exemplos que você citou, qual você considera o menos importante?

3.b Por quê?

O local das entrevistas foi escolhido pelo participante. Foi solicitado que o participante ou o responsável assinasse o termo de consentimento, de acordo com as resoluções do Ministério da Saúde (BRASIL, 1996; Res. 196/1996) e do Conselho Federal de Psicologia (BRASIL, 2000; Res. 016/2000). As entrevistas foram gravadas na íntegra e, posteriormente, transcritas.

Sobre a análise dos dados, Delval (2002) afirma que, quando se utiliza o método clínico, é necessário começar a análise de dados pela análise qualitativa, para a formulação de categorias. Depois que estas estiverem formuladas, é interessante usar uma análise quantitativa, que permite ver com mais clareza as mudanças nas concepções. Desta forma, demos prioridade à análise qualitativa dos dados, mas apresentamos referências quantitativas de acordo com números de respostas ou justificativas.

Assim, para a categorização dos dados realizamos a leitura dos protocolos. Elaboramos, portanto, categorias para as respostas e justificativas dos participantes, para fazer a análise por questão do instrumento. Apresentaremos, a seguir, os resultados e a discussão. 


\section{Resultados e discussão}

Apresentaremos os resultados e a discussão na mesma ordem do instrumento. Assim, primeiro discutiremos sobre os exemplos de amor citados pelos participantes, com suas justificativas; em seguida, qual exemplo de amor seria o mais importante, e por último, qual exemplo de amor seria o menos importante, também com suas respectivas justificativas. Para melhor compreensão dos resultados, explicaremos algumas categorias que julgamos ser necessário.

Em primeiro momento, questionamos aos participantes sobre o que eles consideravam exemplos de amor. Cada participante citou mais de um exemplo. As respostas estão apresentadas na tabela 1 .

\section{Tabela 1}

Distribuição do número de exemplos de amor mencionados pelos participantes de acordo com a idade.

\begin{tabular}{|c|c|c|c|c|c|c|c|c|}
\hline \multirow[b]{2}{*}{ Categoria } & \multicolumn{7}{|c|}{ Participante (Idade em anos) } & \multirow[b]{2}{*}{ TOTAL } \\
\hline & 5 & 10 & 15 & 20 & 30 & 50 & 70 & \\
\hline $\begin{array}{l}\text { Ações de amor por } \\
\text { pessoas em geral }\end{array}$ & 2 & 1 & 5 & 3 & 0 & 0 & 0 & 11 \\
\hline $\begin{array}{l}\text { Amor por uma } \\
\text { pessoa da família }\end{array}$ & 0 & 1 & 0 & 1 & 2 & 0 & 4 & 8 \\
\hline $\begin{array}{l}\text { Amor por um } \\
\text { companheiro }\end{array}$ & 0 & 1 & 0 & 1 & 1 & 1 & 3 & 7 \\
\hline Ações com amor & 1 & 0 & 0 & 1 & 2 & 0 & 1 & 5 \\
\hline Amor por amigo & 0 & 1 & 0 & 1 & 1 & 0 & 2 & 5 \\
\hline Amor a um lugar & 0 & 0 & 0 & 0 & 3 & 0 & 0 & 3 \\
\hline Amor de si & 0 & 0 & 1 & 0 & 1 & 0 & 0 & 2 \\
\hline Outros & 0 & 0 & 0 & 1 & 5 & 1 & 0 & 7 \\
\hline Total & 3 & 4 & 6 & 8 & 15 & 2 & 10 & 48 \\
\hline
\end{tabular}

Considerando os participantes de até 30 anos, percebemos que o número de exemplos citados aumentou com a idade. A categoria ações de amor por pessoas em geral se refere a respostas que indicam ações como cuidar, 
compartilhar e admirar; ações direcionadas a outra pessoa. Temos como exemplo a resposta da Quênia (15 anos) $)^{5}$ : "Estar com a pessoa em qualquer momento [...] independente da situação. Companheirismo". Foi a mais citada, mas somente os participantes de até 20 anos (Caio, Daniela, Quênia e Vanessa) fizeram menção a ela.

Bauman (2004) relaciona o amor com a vontade de cuidar, preservar o objeto cuidado e proteger. No mesmo sentido das respostas dos participantes, amar significaria colocar-se à disposição, estar a serviço, ou seja, uma ação direcionada a outrem. Keleman (1996) também discorre sobre ações quando estabelece os estágios de amor (cuidar, importar-se, compartilhar e cooperar).

Constatamos que, nas respostas dos participantes agrupadas como "ações de amor por pessoas em geral", o amor também está direcionado a outra pessoa, há uma preocupação com ela. E ainda, não há definição de quem seria esse recebedor da ação, podendo ser alguém além da família ou do grupo de amigos. Podemos relacioná-lo com o amor ágape, que é o amor desinteressado e gratuito (COMTE-SPONVILLE, 1999). Entretanto, não podemos afirmar que se trata desse tipo de amor, pois analisando as justificativas para a escolha desses exemplos, que veremos adiante, ainda há uma espera de receber algo pela ação, não sendo totalmente desinteressado. Todavia, esses resultados remetem para uma construção desse tipo de amor.

Questionamo-nos por que esse exemplo não aparece nas respostas dos participantes de 30, 50 e 70 anos. Para responder a essa questão, sugerimos outras pesquisas que investiguem mais detalhadamente a presença de ações no conceito de amor de pessoas nessas faixas etárias.

Agrupamos em "amor por uma pessoa da família" todos os exemplos que citavam o amor relacionado a mãe, pai, filho, neta e genro, ou até mesmo quando já se referia ao amor à família. Das oito respostas incluídas nessa categoria, quatro foram mencionadas por Silvia (70 anos), duas por Thiago (30 anos), uma por Vanessa (20 anos) e uma por Daniela (10 anos).

A resposta "amor por um companheiro" corresponde a todos os exemplos que indicam o relacionamento amoroso, podendo ser o relacionamento próprio ou de outras pessoas. Foi citada por quase todos os participantes (exceto Caio, 5 anos, e Quênia, 15 anos), ou seja, pelos mais velhos. Sendo que Silvia (70 anos) apresentou três das sete respostas.

Outro exemplo citado foi "ações com amor", que se refere a ações que são feitas com amor. A explanação de Silvia e a de Thiago correspondem a essa resposta.

\footnotetext{
${ }^{5}$ Ao nos referirmos a um participante, apresentaremos nome fictício, seguido da idade em anos e trecho da entrevista entre aspas.
} 
Silvia (70 anos): “Quando fazemos uma comida com muito amor";

Thiago (30 anos): "Amor pelo que gosta de fazer também. Por exemplo, eu adoro dirigir”.

Percebemos que aqui o amor seria o "combustível" para a realização de uma atividade. Nesta categoria o outro não aparece como recebedor dessa ação, como nas "ações de amor por pessoas em geral".

Mais da metade dos participantes citaram "amor por um amigo" como exemplo de amor, (exceto Caio, 5 anos, Quênia, 15 anos e Célio, 50 anos). Já a categoria "amor por um lugar" apenas foi referida por Thiago (30 anos), com três exemplos.

Os participantes também responderam sobre "amor de si", indicando o amor a si mesmo. Esta resposta só foi citada por Quênia (15 anos) e Thiago (30 anos). Vejamos o que eles dizem.

Quênia (15 anos): "Porque se você não se ama, você não consegue amar os outros".

Thiago (30 anos): "Antes de você gostar dos outros, você tem que gostar de si mesmo. [...] Porque a partir do momento que você gostar de você, você irá usar isso para gostar das outras pessoas".

Para os participantes há necessidade do amor de si, para, a partir dele, poder amar. Estes exemplos divergem da concepção de Bauman (2004) sobre o amor-próprio, pois, segundo ele, para termos amor-próprio, necessitaríamos de ser amados, pois o que amaríamos em nosso amor-próprio seria nosso estado, ou esperança, de sermos amados. Ou seja, primeiro o outro nos amaria, para desencadear nosso amor-próprio.

Os exemplos citados pelos dois participantes remetem a outrem, concordando, portanto, com a afirmação de Betto (BETTO \& CORTELLA, 2007; p. 55) de que "não há como gostar de alguém sem gostar de si", ou seja, temos que nos amar, para amar o outro. Para La Taille (2006) o "amor próprio" não seria suficiente para garantir a moral, é necessário acrescentar um valor moral e ético para não levar à imoralidade, que é o amor de si.

Em "outros" agrupamos os exemplos citados apenas uma vez, como amor dos cuidadores, por animal, por coisas materiais, pelo time de futebol, a Deus, de fã pelo seu ídolo e de Mahatma Gandhi (1869-1948).

Fazendo uma análise por entrevistado podemos constatar que os acima dos 30 anos, no lugar de apresentarem respostas sobre "ações de amor por pessoas em geral", esses participantes citam mais "amor por uma pessoa da família", "amor por um companheiro" e "amor por um amigo". Desta forma, o amor está direcionado apenas a pessoas próximas (família, amigos ou companheiro). 
Depois que os participantes citavam todos os exemplos, pedimos que argumentassem o porquê consideravam aquele como exemplo de amor. Assim, todas as respostas têm pelo menos uma justificativa, sendo que estas estão apresentadas na Tabela 2 .

\section{Tabela 2}

Distribuição do número de justificativas dos participantes para os exemplos de amos de acordo com a idade.

\begin{tabular}{|c|c|c|c|c|c|c|c|c|}
\hline \multirow[b]{2}{*}{ Categoria } & \multicolumn{7}{|c|}{ Participante (idade em anos) } & \multirow[b]{2}{*}{ TOTAL } \\
\hline & 5 & 10 & 15 & 20 & 30 & $\mathbf{5 0}$ & 70 & \\
\hline Experiência vivenciada & 2 & 0 & 0 & 0 & 7 & 4 & 17 & 30 \\
\hline Conseqüência positiva & 0 & 5 & 5 & 3 & 9 & 0 & 6 & 28 \\
\hline Sentimento & 0 & 1 & 1 & 3 & 6 & 0 & 8 & 19 \\
\hline $\begin{array}{l}\text { Característica própria do } \\
\text { amor }\end{array}$ & 0 & 0 & 0 & 1 & 10 & 0 & 4 & 15 \\
\hline Cuidado & 1 & 0 & 0 & 8 & 0 & 0 & 0 & 9 \\
\hline Necessidade & 0 & 0 & 2 & 1 & 1 & 0 & 0 & 4 \\
\hline Outros & 1 & 1 & 2 & 1 & 4 & 0 & 0 & 9 \\
\hline Total & 4 & 7 & 10 & 17 & 37 & 4 & 35 & 114 \\
\hline
\end{tabular}

Em "experiência vivenciada" consideramos tanto as justificativas que falam da experiência própria quanto à vivida por outras pessoas. Apresentaremos, respectivamente, exemplo de experiência própria e de vivida por outra pessoa.

\footnotetext{
Silvia (70 anos): "Porque a gente serve as pessoas com muito carinho, fica muito bom, muito gostosa. [...] Se for fazer aquilo aborrecida, magoada, aquilo não fica bom. E com amor, com carinho, a gente já sente que o prato que a gente fez se tornou uma coisa boa, interessante".

Célio (50 anos): "Porque ele pregava a luta contra a violência".
}

Podemos observar que esta justificativa teve maior freqüência (30 respostas). Foi mencionada pelos participantes maiores de 30 anos (Thiago, 
Célio e Silvia), e pelo de 5 anos (Caio). Somente a Silvia (70 anos) apresentou 17 dos 30 argumentos dessa categoria. Percebemos que os mais velhos utilizam da sua experiência e da experiência de outros para justificar a escolha do exemplo de amor. O mais novo (5 anos) utiliza de sua experiência mais próxima para dizer sobre sua escolha. Vejamos sua fala: "Porque eu brinco com o Marcelo, com o Rodrigo, com o Hélio. São todos meus amigos".

Agrupamos em "consequiência positiva" argumentações que remetiam à consequiência positiva do exemplo citado, podendo ser uma consequiência positiva a própria pessoa (17 justificativas), direcionada a outro (sete justificativas) ou recíproca (quatro justificativas). Vejamos três explanações, cada uma correspondendo, nessa ordem, a um tipo de conseqüência positiva.

Daniela (10 anos): "Porque quando eu preciso de
alguma coisa eles sempre me ajudam";
Vanessa ( 20 anos): "Quando você ama alguém, você
cuida para o bem dessa pessoa";
Vanessa ( 20 anos): "Para que ela se sinta bem, para
que você também se sinta bem".

Os participantes também justificaram seus exemplos pelo "sentimento", podendo este ser próprio, de outra pessoa ou de uma forma geral. Para facilitar a compreensão, vejamos três justificativas nessa ordem:

Thiago (30 anos): "Porque eu adoro coisa antiga"; Silvia (70 anos): "Porque ele gosta muito de mim"; Vanessa (20 anos): "Porque envolve tudo que eu falei, carinho, afeto, atenção".

As justificativas pela "consequiência positiva" e pelo "sentimento" foram dadas por quase todos os participantes, exceto o Caio (5 anos) e o Célio (50 anos). Para Bauman (2004), quando se investe em uma relação, se espera o lucro da segurança, "em muitos sentidos: a proximidade da mão amiga quando você mais precisa dela, o socorro na aflição, a companhia na solidão, o apoio para sair de uma dificuldade, o consolo na derrota e o aplauso na vitória" (p. 28/29). Isso está de acordo com o alto número de respostas (28 respostas) que remete à conseqüência positiva do exemplo citado, principalmente, em relação a um ganho que o exemplo escolhido pode resultar para própria pessoa (sendo 17 das 28 respostas).

"Característica própria do amor" refere-se ao fato do amor ser inerente e incondicional; por sua intensidade, durabilidade e veracidade; pelo fato de ser construído e pela ausência de ganho pessoal. Das 15 argumentações aqui agrupadas, 10 foram citadas por Thiago (30 anos). 


\title{
Hüüăas
}

A categoria "cuidado" foi referida oito vezes por Vanessa (20 anos) e uma por Caio (5 anos). Já as justificativas pela "necessidade" foram dadas por Quênia (15 anos), Vanessa (20 anos) e Thiago (30 anos). Vejamos a fala de Quênia sobre "necessidade": "Porque você precisa de alguém".

Em "outros" agrupamos as justificativas sobre importância do amor, por ser uma coisa correta, pela proximidade, pelo limite, pelos projetos em comum, pela lealdade, por não ter explicação para o exemplo escolhido e pela importância da família; sendo que somente a última foi citada duas vezes, as outras, apenas uma.

Discutiremos agora sobre a segunda questão do nosso roteiro, qual exemplo de amor seria o mais importante. Cada participante elegeu um exemplo, somente o Célio (50 anos) não conseguiu responder a questão. Caio (5 anos), Daniela (10 anos) e Quênia (15 anos) consideraram exemplos que correspondem a "ações de amor por pessoas em geral". Eis respectivamente seus depoimentos:

\author{
Caio (5 anos): "não machucar". \\ Daniela (10 anos): "saber compartilhar". \\ Quênia (15 anos): "entender a outra pessoa". \\ Thiago (30 anos) relacionou o "amor a Deus". Va- \\ nessa (20 anos) e Silvia (70 anos) citaram o "amor \\ por uma pessoa da família", sendo que a última \\ especificou o amor a neta.
}

Voltemos à tabela 1 e verificamos que, de todos que citaram pelo menos um exemplo de "ações de amor por pessoas em geral", somente a Vanessa (20 anos) não elegeu este como exemplo de amor mais importante. Assim, até os de 15 anos, as 'ações de amor por pessoas em geral' são exemplos de amor considerados mais importantes. Na participante de 20 anos este exemplo é citado, mas já não recebe destaque. Por sua vez, a partir dos 30 anos os entrevistados nem citam as "ações de amor por pessoas em geral". Ressaltamos, novamente, a importância do outro para esses participantes de 5, 10 e 15 anos, ou seja, uma possível gênese do amor ágape. No entanto, essa hipótese precisa ser mais bem investigada. Se assim for, o que acontece com o amor ágape no decorrer do desenvolvimento?

Entretanto, apesar de não ter citado "ações de amor por pessoas em geral", o Thiago (30 anos) destaca o "amor a Deus" como mais importante. Refere-se, portanto, ao amor ágape, que, como afirma Comte-Sponville (1999) é o amor divino. O único que citou esse exemplo como sendo um exemplo de amor destacou-o como mais importante. Esse exemplo pertenceu à categoria "outros" da Tabela 1, por ter sido citado apenas uma vez. 
Passemos agora para a justificativa da escolha do exemplo de amor mais importante, sendo que alguns participantes deram mais de uma. Assim, temos um total de 14 justificativas; sendo que uma foi considerada "dado perdido", pois Célio não respondeu a questão anterior.

Um argumento para a escolha dos exemplos foi a "conseqüência do objeto de amor" (três justificativas), sendo dadas por Caio (5 anos) e Daniela (10 anos), sendo que Daniela a citou duas vezes. Eis o que ela disse: "Porque assim [entendendo a outra pessoa] não teremos dificuldades no relacionamento". E ainda, "[entendendo a outra pessoa] vamos ter mais amigos".

"Importância do objeto de amor" (três argumentos) foi mencionada uma vez por Vanessa (20 anos) e duas vezes por Thiago (30 anos). Exemplifiquemos com o argumento de Vanessa: "Porque eu acho que [a família] é a base". Esta importância também é clara quando Thiago, que escolheu Deus como mais importante, justifica sua escolha: "Porque [Deus] está acima de qualquer coisa. [...] Todas as coisas giram em torno Dele".

Somente Silvia (70 anos) se referiu a "característica própria do objeto de amor" (três justificativas) e a "sentimentos" (duas justificativas). Tendo escolhido sua neta, como exemplo mais importante, Silvia justifica sua escolha pela característica da neta e pelo sentimento que sente por ela. Vejamos um exemplo de cada categoria, respectivamente:

\footnotetext{
Silvia (70 anos): "É porque ela [a neta] trabalha muito, ela se dá assim muito nos estudos. [...] Porque ela é nova e não entende muito da vida, para estar nessa luta tão grande";

Silvia (70 anos): "Porque é um amor muito grande que eu sinto por ela".
}

Outra justificativa mencionada foi a "necessidade do objeto de amor" (dois argumentos), sendo citada por Quênia (15 anos) e por Thiago (30 anos). Quênia afirma que "Porque você precisa de alguém que te compreenda".

Discutiremos a última questão, sobre qual exemplo de amor seria o menos importante. Célio (50 anos) também não respondeu a essa pergunta. É importante ressaltar o fato de duas participantes (Quênia, 15 anos, e Vanessa, 20 anos) não conseguirem definir um exemplo de amor menos importante, elas afirmaram que 'não existe' um menos importante, pois consideram todos os exemplos citados essenciais. Para a concepção que elas têm, se é amor, já seria, portanto, importante e essencial.

Por sua vez, Daniela (10 anos) e Silvia (70 anos) estabeleceram o "amor por amigo" como exemplo menos importante. Thiago (30 anos) elegeu o "amor a coisas materiais". Já Caio (5 anos) citou uma "ação com amor", com a afirmação de que o exemplo de amor menos importante é "brincar com os amigos". 


\section{HUMANAS}

Vejamos as justificativas para a escolha do exemplo de amor menos importante. Dos sete participantes da pesquisa apenas quatro (Caio, Daniela, Thiago e Silvia) justificaram essa resposta. Isto porque tivemos dois "dados nulos", já que a Quênia (15 anos) e a Vanessa (20 anos) afirmaram não possuir um exemplo menos importante, e um "dado perdido", pois o Célio não conseguiu responder a questão.

As justificativas se referem a "pouca durabilidade", citada por Caio (5 anos) e por Silvia (70 anos). Vejamos o argumento de Caio: "Porque eu não acho muito importante não [brincar com amigos]. Eu posso brincar pouco tempo".

Caio também justificou pela "possibilidade de substituição": "Porque eu posso brincar com outras pessoas". Daniela (10 anos) relacionou a "pouca quantidade do objeto de amor": "Porque eu tenho poucos amigos". E Thiago (30 anos) fundamenta sua escolha pela "futilidade" do exemplo eleito.

Esses argumentos remetem a discussão de Bauman (2004) sobre o "amor líquido". Ele afirma que devemos saber até quando permanecer na relação, estar sempre atento quando melhores propostas aparecerão. Ressalta a fragilidade das relações, as pessoas se apaixonam e desapaixonam numa velocidade crescente. Remete, portanto, à constante "possibilidade de substituição" e a "pouca durabilidade".

\section{Considerações finais}

É importante destacarmos que os exemplos de amor mais citados foram ações de amor direcionada a outrem, sendo referidos pelos mais novos, o que remeteria a um 'olhar' ao outro. Considerando todos os exemplos, a maioria das justificativas para suas escolhas está em torno da experiência pessoal, ou de exemplos de outras pessoas. Quanto ao exemplo mais importante, podemos relacionar a um princípio de amor ágape, já que apesar de remeter a um amor a Deus ou a uma preocupação ao outro, ainda está presente a justificativa relacionada a quais consequiências teria desse amor. Sobre o exemplo de amor menos importante, duas participantes não conseguiram eleger, pois acreditavam que, sendo amor, já seriam importantes. Para os que escolheram um amor menos importante, suas justificativas remetem a uma fragilidade da relação com o objeto de amor citado.

Assim, apesar de verificarmos essa fragilidade em algumas concepções de amor, podemos analisar seus "poréns", como faz La Taille (2009), e ressaltar também essa preocupação com outrem, que foi tão presente nas respostas dos participantes. A partir disso, concordando com La Taille (2009), destacamos a importância do trabalho sobre as virtudes. E ainda, segundo Betto e Cortella (2007), o papel da educação seria despertar a construção das virtudes. Enquanto não se tornam hábitos, é necessário cuidar para que as elas se desenvolvam. 
Como discutimos anteriormente, Comte-Sponville (1999) afirma que só existe a moral por falta de amor, e quando há o amor, as outras virtudes seguem espontaneamente. Assim, pretendendo explorar o que nossos participantes consideram como sendo amor, destacamos como relevante o incentivo a discussões sobre as outras formas de amor, como a caridade.

Apesar de termos entrevistado um participante de cada idade, pudemos perceber algumas diferenças quanto sua concepção de amor. Sugerimos que outras pesquisas possam ser feitas sobre este tema, com maior número de participantes, para que possa investigar com mais clareza essas mudanças. E ainda se há diferenças quanto a gênero.

\section{Referências Bibliográficas}

BAUMAN, Z. Amor líquido: sobre a fragilidade dos laços humanos. Rio de Janeiro: Editora Zahar, 2004.

BEE, H.L. O ciclo vital. Porto Alegre: Artes Médicas, 1997.

BETTO, F. \& CORTELLA, M.S. Sobre a esperança: diálogo. Campinas: Editora Papirus, 2007.

BRASIL - Ministério da Saúde. Resolução 196/1996: Diretrizes e normas regulamentadoras de pesquisas envolvendo seres humanos. Brasília: Disponível em: http://www.conselho.saude.gov.br (acesso em 5 de Agosto/2009).

BRASIL - Conselho Federal de Psicologia. Resolução 016/2000: Diretrizes e normas regulamentadoras de pesquisas em Psicologia com seres humanos. Brasília: CFP, 2000.

COLL, C.; MARCHESI, A. \& PALÁCIOS, J. Psicologia Evolutiva. In: COLL, C.; MARCHESI, A. \& PALÁCIOS, J. (Orgs.). Desenvolvimento psicológico e educação. Porto Alegre: Artmed, 2004.

COMTE-SPONVILlE, A. Pequeno tratado das grandes virtudes. São Paulo: Editora Martins Fontes, 1999.

DELVAL, J. Introdução à prática do método clínico: descobrindo o pensamento das crianças. Porto Alegre: Artmed, 2002.

KELEMAN, S. Amor e vínculos: uma visão somático-emocional. São Paulo: Summus, 1996.

LA TAILLE, Y. Prefácio à edição brasileira. In: PIAGET, J. O juízo moral na criança. p. 7-20. São Paulo: Summus, 1994. 
LA TAILLE, Y. Para um estudo psicológico das virtudes morais. Educação e pesquisa, 26(1): 109-21, 2000.

LA TAILLE, Y. Moral e ética: dimensões intelectuais e afetivas. Porto Alegre: Artmed, 2006.

LA TAILlE, Y. Formação ética: do tédio ao respeito de si. Porto Alegre: Artmed, 2009.

PIAGET, J. O juízo moral na criança. 2ª Edição. São Paulo: Summus, 1994.

PIAGET, J. Introdução - Problemas e Métodos. In: PIAGET, J. A representação do mundo na criança. Pp. 9-31. Aparecida: Idéias e Letras, 2005.

SHAFFER, D.R. Psicologia do desenvolvimento: infância e adolescência. São Paulo: Thomson, 2005. 